\title{
"Building Defects Management Program" Under Soft Landings Level 3 Performances at Public Universities in Malaysia
}

\author{
Julia Mohd Nor, Adi Irfan Che-Ani, Afaq Hyder Chohan, Wahiza Wahi, Afifuddin Husairi Hussain
}

\begin{abstract}
Numerous studies have been carried out on potential factors or characteristics affecting building performance with regards to defects. Statistics in past research shows significant differences in characteristics between building projects with no or few defects as compared to those with many and/ or serious defects at handover. Within the past decades, series of fault and technical failures in government new buildings have caused a very disturbing situation to the construction industry in Malaysia. Numerous efforts followed-up but issues are yet to be resolved. A study is proposed to determine whether the number of defects at handover can be reduced by introducing new P13 Checklist item named Building Defects Management Program under Soft Landings Framework Level 3 approach. Under this program, the team should review JKR 203A Form of Contracts with PWD personnel authorised as a policy maker to revise the existing Form of Contracts to help reduce the number of building defects at handover should it be viable to do so. Building Defects Management Program will be set up on samples from 3 selected public universities within Klang Valley area to identify the relationship between defects during building handover and Soft Landings Framework Level 3 approach. Stakeholders' verification is thus required on potential revision to be made on existing JKR 203A Form of Contracts among which are the positioning of As-built Drawings as a Preliminary item, the option of using “WJP” (Wang Jaminan Pelaksanaan) as retentions rather than Performance Bond, release of $50 \%$ of Performance Bond after CPC is issued and also O\&M manuals being part of the Contracts instead of being part of CCC mandatory submissions. The outcome of the study is expected to affirm the relationship between defects during handover and Soft Landings Framework Level 3 approach at public universities in Malaysia.
\end{abstract}

Keywords: Defects, Soft landings, building handover, public universities, Malaysia

\section{INTRODUCTION}

University building is a collection of buildings that belong to a given institution, either academic or non-academic. These buildings and grounds which include the colleges,

Revised Manuscript Received on June 22, 2019.

Julia Mohd Nor, Centre of Architecture and Innovative Built Environment (SErAMBI), Faculty of Engineering and Built Environment, Universiti Kebangsaan Malaysia (UKM).

Adi Irfan Che-Ani, Centre of Architecture and Innovative Built Environment (SErAMBI), Faculty of Engineering and Built Environment, Universiti Kebangsaan Malaysia (UKM). Pusat Citra Universiti (Citra UKM), UKM.

Afaq Hyder Chohan, Pusat Citra Universiti (Citra UKM), UKM.

Wahiza Wahi, Pusat Citra Universiti (Citra UKM), UKM.

Afifuddin Husairi Hussain, Pusat Citra Universiti (Citra UKM), UKM.
Residence halls, faculties with lecture halls, laboratories and Offices; student centres, libraries, administration buildings and park-like settings, are situated on the land which we traditionally called campus.

Under the current Malaysian Plan or 11MP (2016-2020), the Government aims to boost the current 25 percent of students pursuing education in technical and vocational training to 35 percent, at par with academic and professional graduates. For universities to produce high-skilled workers that the market wants by 2020, 1 billion ringgit has been allocated to achieve the acquired Technical and Vocational Education and Training (TVET) graduates, compared to 500 million ringgit in the previous Plan period. Functional universities are needed to support this Plan and university buildings are the most important functional assets to realise this.

However, Abdul Lateef Olanrewaju, A. (2012) claims that there have been many complaints and criticisms in media and research literatures with the performance of university buildings in Malaysia on account of poor maintenance management despite the consistent increase in maintenance expenditures. The aim of this paper is to propose a study on potential application of Building Defects Management Program under Soft Landings Level 3 (Pre-Handover) approach at public universities in Malaysia. The intention is to investigate the extend of Soft Landings approach applied by selected public universities' project team members involved. The main objective is to determine whether the number of defects of new building at handover can be reduced by developing new P13 Checklist item under Soft Landings Level 3 (Pre-Handover) named Building Defects Management Program.

\section{Building Defects}

Defects within new buildings can be defined as areas of non-compliance of a completed building against building specifications and standards as per specified in the Contract. These defects may be results of sub-standard work or lack of expertise at time of construction. However, for older buildings or buildings out of warranty period, defects which may be caused by lack of maintenance must be judged against the standards at that point of time. Joint inspections are expected to be carried out by both technical professionals and users to record defect items that require attention. Examples of building defects are structural settlement cracks, hairline cracks on walls, sagging ceilings, poor-fitting windows and doors, leaking shower, improper installation of basic amenities

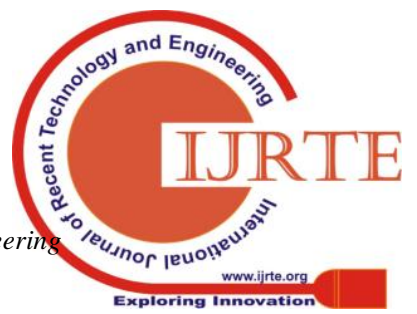


In bathrooms, non-compliance with termite system and many others.

Building designs are becoming not just more complex these days but also more important. Better building

Technologies will simply fail if they are not well-designed and integrate from the time of inception. Great design which puts all the elements together in the right way, effective project management as well as dedicated teamwork is the only way to get good results as per acquired by stakeholders. Having said that, we also have to bear in mind that the product of such acquired building is constrained by whether it is designed to budget or designed to needs. This is where expertise of professionals and collaboration between stakeholders come together in order to come up with what is expected from them. However so, handing over a building from the main contractor to client/building owner as per say, is the crucial part where listed defects at this point are merely under full liability of the main contractor. With the complexity of construction work itself within uncontrolled environment, such defects cannot be put to zero unless proper guidelines are in-placed to ensure that building is handed over with minimal possible defects. Preventive measures need to be considered at the earliest possible of project cycle, amongst others, is to review the existing contractual requirements directly involved with building defects.

A study carried out by Abdul Lateef Olanrewaju, A. (2012) on a survey based on sampling by convenience on 550 university building users from five selected universities in Malaysia emphasizes that samples are directed towards defects that affect security, safety and comfort. A total of 20 defects were found to be very critical to the building users which included faulty electrical systems, faulty airconditioning systems and roof damages. This study which is concerned with defects in university building maintenance from the user point of view is expected to contribute towards improving communications for all involved in issues related to defects in university buildings.

Another study by Schultz, C.S. et al. (2015) on two quantitative data sets: (1) benchmarking data from 329 building projects and 621 contracts and (2) questionnaire data from an electronic survey comprising 130 contractors shows statistically significant differences between building projects characterized by no or few defects compared with building projects with many and/ or serious defects. The study indicates that the number and severity of defects at handover are a manifestation of the quality at a certain impact point i.e. the time of the handover. However, a wellexecuted and well-managed building process and an effective quality management system will increase the output quality and hence decrease the number of defects at handover. This study indicates that collaboration between stakeholders plus skills and safety initiatives as having a positive influence on the performance measured as defects at handover.

\section{Building Defects and Management in Malaysia - A Literature Review}

Within the past decades, series of fault and technical failures in government new buildings have caused a very disturbing situation to the construction industry in Malaysia.
Numerous efforts followed-up but issues have yet to be resolved. Comparison made on past Malaysian Plan budget distribution shows an outstanding escalation on the provisions of development planning for repairs and maintenance works from 8MP to 9MP. According to the 9MP (CIDB Press, Fourth Edition 2006), the allocation for maintenance works had increased from RM296 million in 8MP (2001-2005) to RM1.079 billion in 9MP (2006-2010) with an increase of $264.5 \%$ to be spent within those 5 intended years. The huge budget allocated for these maintenance works which includes newly completed buildings shows a serious and extensive buildings defects issues on government buildings in Malaysia.

Zawawi and Kamaruzzaman (2010) emphasized that maintenance works took the spotlight when multiple of government owned buildings were hit by precedented failures, causing an alarming situation for construction and maintenance contractors (Eizzatul Ain, S., Hishamuddin, M.A. and Suwaibatul Islamiah, A.S., 2012).Among all nationwide speculated failures on building performance, lessons could be learned from one of the most horrific structural defects and technical failures ever happened in Malaysia i.e. the Kuala Lumpur Courts Complex (Kompleks Mahkamah Kuala Lumpur). This complex was constructed beginning 1 March 2004 and was completed with a final cost of RM290 million. Problems were reported to have started even before occupancy. Cracks measuring at least $3 \mathrm{~m}$ long were reported in early April. The building was opened for use on 18 April 2007 and just over a week after occupancy, two (four feet by four feet) ceiling panels and a down light collapsed in a Civil Court on 30 April 2007, followed by more cracks outside Magistrate's Court 4. Situation worsened as air conditioning in High Court room became malfunctioned and burst of pipe end cap from a service room added on by overflow from sewage manhole had caused flooding at the complex cafeteria. (Star, 25 April 2007; Sun, 25 May 2007)

Another example was the Sultan Mizan Zainal Abidin Stadium in Kuala Terengganu. This multi-purpose stadium named after the reigning Terengganu Ruler, was built by a South Korean construction firm for a capacity of 50,000 people and a total cost of RM292.9 million. The stadium was officiated on 10 May 2008 but part of the main stadium roof steel frame including the section above the royal box collapsed under normal weather about a year later. It collapsed for the second time during re-construction work and approximately RM100 million was spent to repair the overall stadium facilities. (Star, 3 June 2009, 20 February 2013; Bernama, 21 February 2013; Utusan, 3 June 2009)

Based on studies carried out abroad, defects in construction have become quite a common concern among the academia and the public worldwide. Investigations on quality problems related to both processes and products in the construction industry have often been made focussing on quality costs, for example cost of rework, cost of failure etc. Research also shows that the phenomenon of nonconformance has been devised by different related and often 
Interrelated terms such as errors and failures (Love, Lopez \& Edwards, 2013), human errors (Love \& Josephson, 2004), deficiencies and quality deviations (Burati, Farrington \& Ledbetter, 1992) and also defects (Josephson \& Hammarlund, 1999).

Mark Way (2005) concludes that "zero defects" approach to construction has been a world-wide talk for decades but to-

date, the construction industry has been slow at learning from buildings in use because it does not get close to its user clients.

With regards to the pending issues on building defects in government new buildings in Malaysia, it is about time especially for us as construction practitioners to think and work beyond the given box to shift from what we have been practising for the past decades with regards to the current process or procedures. It is thus apparent that Soft Landings Framework is a potential approach to look into and perhaps to be considered as future implementation in Malaysia.

\section{Soft Landings for Building}

Soft Landings is a process for a graduated handover of a new or refurbished building, where a period of professional aftercare by the project team is a client requirement and planned for and carried out from the project inception onwards and for up to three years post-completion (Rod Bunn, BSRIA, 2012).

Soft Landings for building was born in the late 1990s devised by architect Mark Way which preliminary documentation was later developed in the form of scope of service document in 2004 with construction sponsorship. It was not until 2009 when Soft Landings Framework was finally authored by Buildings Services Research \& Information Association (BSRIA), UK and Usable Buildings Trust (UBT). The scope and knowledge of this framework were then broadened within Australia and New Zealand. In 2014, the rights to use and adapt the content of this Soft Landings Framework was granted by BSRIA to the Australian and New Zealand Region of the Chartered Institution of Building Services Engineers (CIBSE ANZ).

Traditionally, buildings are simply handed over to the client with list of defects jointly recorded by representatives from building team and end-user, after which contractor is expected to carry out necessary remedial works within the given time frame. By contrast, 'Soft Landings' which exists in some parts of the construction industry enables end-user involvement at early stages and throughout project to ensure that building to be built meets the end users' needs and required operational outcomes. It also ensures that full training, commissioning and handover is provided at an early stage and thus reducing the cost of protracted handover. The Soft Landings approach will not only ensure that the built asset reach optimal performance sooner but also ensures lessons are learned for future projects via its 3 years post completion (POE) monitoring on building performance.

According to Buildings Services Research \& Information Association (BSRIA), UK (2012), Soft Landings philosophy is a way of working that says that we have to change the way we do things to deliver better buildings and it is also designed to foster greater mutual understanding between clients, project managers, designers, builders and occupiers about project objectives to ensure that clients and occupiers get the best out of their new asset. It also involves greater investment in problem diagnosis and treatment, and in monitoring, review and post-occupancy evaluation.

\section{Soft Landings Framework}

As mentioned earlier, Soft Landings Framework is a joint initiative between BSRIA and UBT published in 2009. It was later updated in 2014 to align with the RIBA (Royal Institute of British Architects) 2013 work stages shown in Figure 1and is currently being developed by the BSRIA Soft Landings Group.

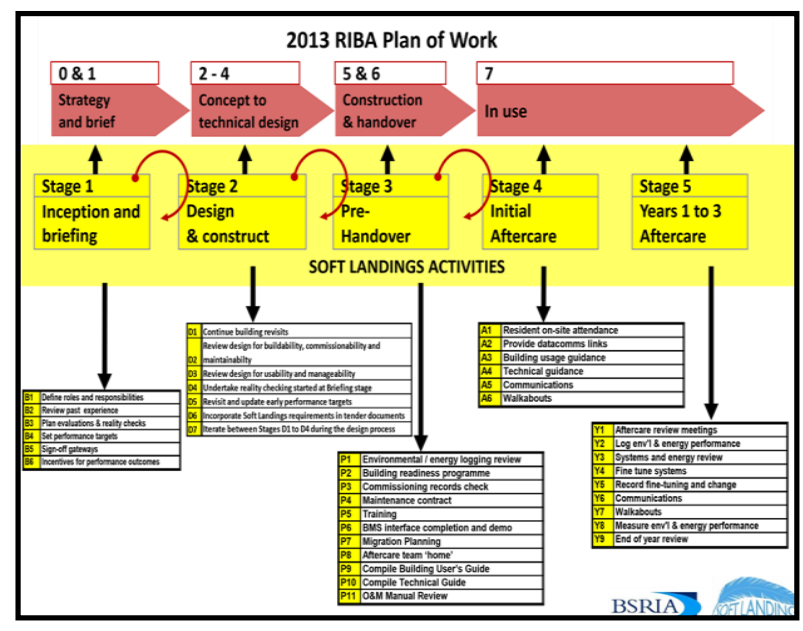

Fig. 1 RIBA Plan of Work 2013 (Morgan Sindall, BSRIA, 2014)

The Soft Landings Framework originally included 5 key stages:

1) Inception and briefing

Clarify operational outcomes in the client's requirements

2) Design development and review

- Review past experience, agree performance metrics, agree design targets, regularly reality-check

3) Pre-handover

- Prepare for occupation, train FM staff, demonstrate control systems, review monitoring strategy of occupants and energy use

4) Initial aftercare

- Support occupants in first few weeks of occupation, be resident on site to respond to queries and react to emerging issues

5) Extended aftercare and post occupancy evaluation (POE)

- Monitor, review, fine-tune and perform periodic feedback studies for up to three years to reach performance targets

These 5 key stages can be illustrated as shown in Figure 2 . 


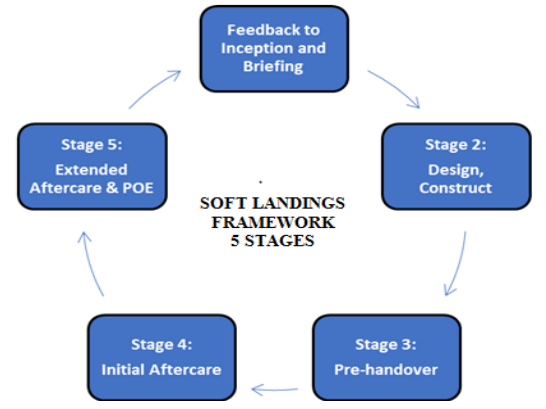

Fig. 2 The Soft Landings Framework (BSRIA, 2014)

In August 2018, BSRIA launched the latest version of Soft Landings Framework 2018 - a 6 Phases Approach for Better Buildings. This new framework adopts 6 stages in place of the previous 5 stages, separating out design and construction activities to strengthen the construction content:

1. Inception and briefing

2. Design

3. Construction

4. Pre-handover

5. Initial aftercare

6. Extended aftercare and post occupancy evaluation (POE).

However, this proposed study will be based on 5 stages version of Soft Landings Framework Australia and New Zealand (CIBSE ANZ 1/2014).

\section{METHODOLOGY}

The proposed research will be delivered according to the following phases:

\section{Building Defects Management Program in SL identified}

Based on literature reviews published worldwide, Soft Landings Framework was born in the late 1990s and is currently adapted only in UK, Australia and New Zealand. SL Framework includes 5 key stages from which Level 3 (Pre-Handover) has been chosen by student as the focus of this proposed research. SL Framework Level 3 (PreHandover) consists of Checklist P1 up to P12. These Checklist P1 - P12 are apparently concerned only with mechanical and electrical requirements, building management system interface and allied controls, O\&M manuals and maintenance manuals (after handover) but none is related to physical building defects at handover. As such, this Building Defects Management Program was created as Checklist P13 of SL Framework Level 3 in parallel with existing contractual guidelines that is our JKR 203A Form of Contracts which our local construction industry is borne with.

\section{Building Defects Management Program Framework is developed}

In reference to our long pending issues on poor delivery of completed buildings with regards to defects at handover, our existing JKR 203A Form of Contracts is the key that binds project team members i.e. the Consultant team, Contractor, Client / End-users. As such, Checklist P13 named Building Defects Management Program under Level 3 has to be developed in order to proceed with the intended scope of research. This Building Defects Management Program will relate to contractual items spelled out in JKR 203A observed to be among the most common items contributing to defected buildings at handover. In order to carry out this proposed research successfully, we will introduce the new checklist item P13 named Building Defects Management Program as the focus under Level 3 Pre-Handover:

\section{Building Defects Management Program}

The team should review JKR 203A Form of Contracts with PWD personnel, who has the authority as policy maker to revise the existing Form of Contracts to help reduce the number of building defects at handover. The variables need to be tested as well to the consultant \& contractors, who are the main players in the construction industry. In analysing this, we will use SEM SMART-PLS. The other stakeholders involved is CIDB (Construction Industry Development Board) and building owners.

\section{Stakeholder input verified}

In this study, samples will be taken from completed projects (preferably in use for 3 years and below) at 3 selected public universities within Klang Valley. We will explore the construction history of selected projects and identify the approach taken in the preparation of new buildings. We will also identify the relationship between defects during building handover and SL approach.

\section{Building Defects Management Program in SL is fully developed}

Finally, we will set up SL Framework Level 3 model where views and feedback will be obtained from stakeholders. Feedback on these contractual items will be used as the basic foundation for us to sit down with PWD personnel and CIDB on the possibility of proposing the revision of the existing Form of Contracts to help reduce the number of building defects at handover.

\section{Stakeholder acceptance verified}

The outcome from this study will be based on the conclusive or overall remarks obtained from PWD personnel, CIDB, consultant and main contractor who are authorized as part of policy maker team in Malaysia with regards to our construction industry. It is also hoped that further effort can be taken (following this research) to table up the issues, proposed revision on some JKR 203A Form of Contracts items, as well as proposed implementation of Building Defects Management Program to the Cabinet of Malaysia for approval.

The flowchart of the proposed study can be presented as shown in Figure 3 below. 


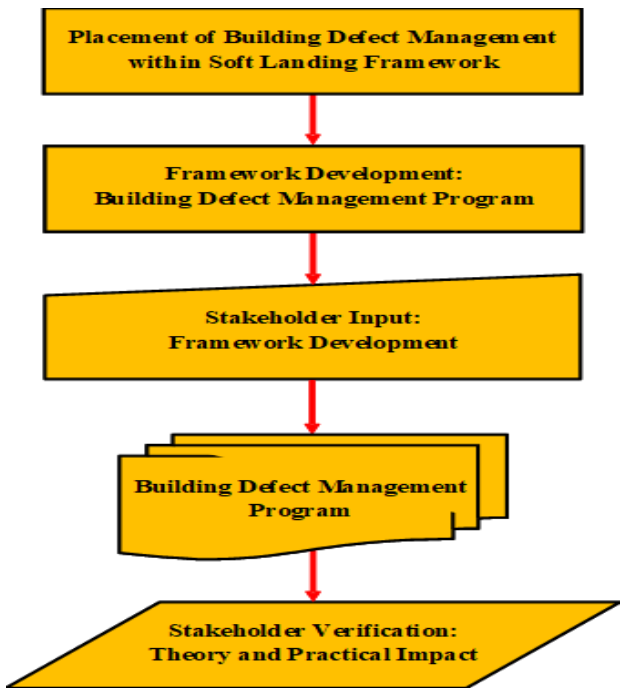

Fig. 3 Flowchart on Soft Landings Framework Level 3 Approach on Public Universitiesin Malaysia

\section{Soft Landings Framework Level 3 - Pre-Handover}

The checklist for Stage 3 - Pre-Handover adapted from Soft Landings Framework Australia and New Zealand (Soft Landings Framework ANZ) is listed in Figure 4below:

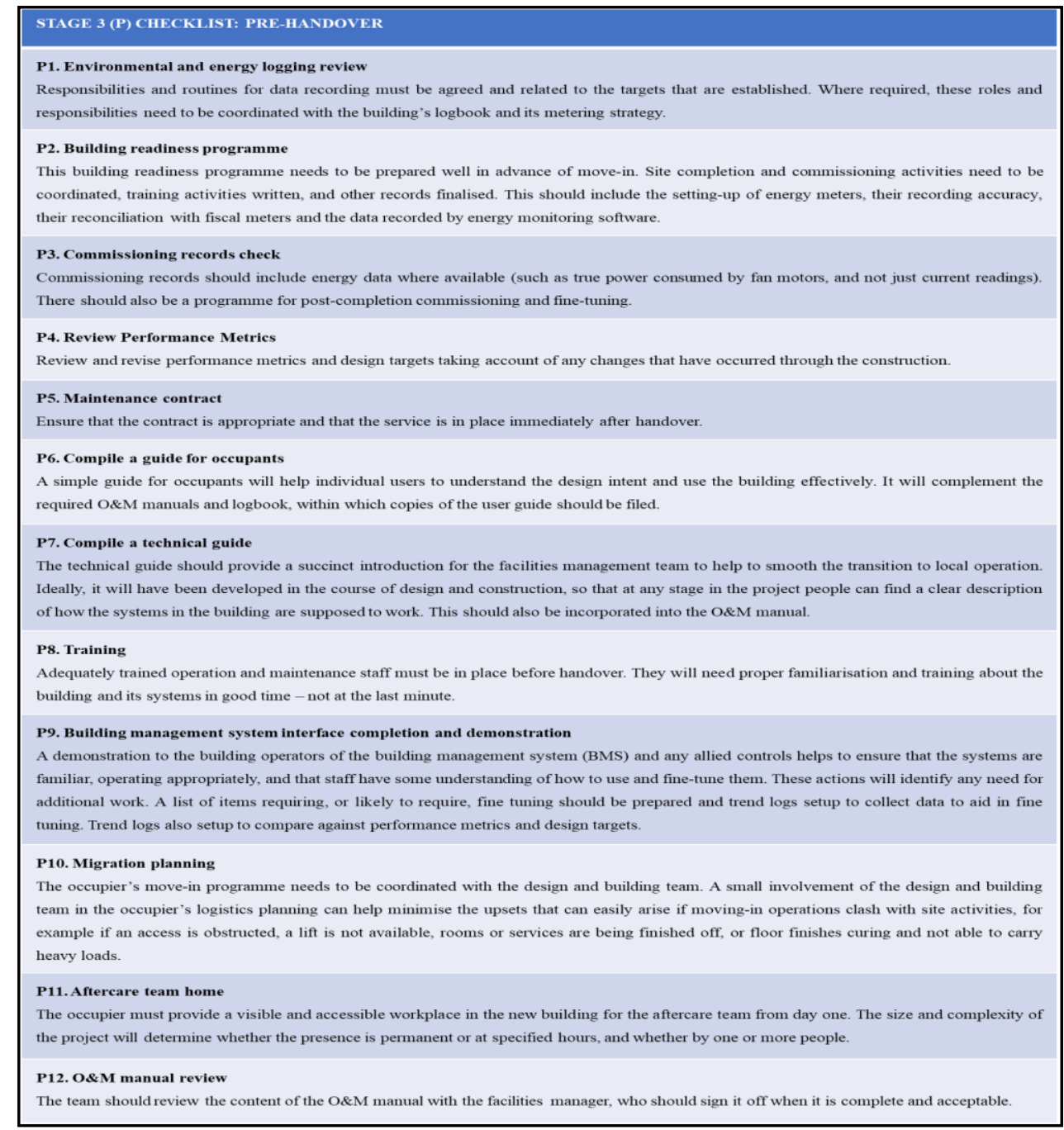

Fig. 4 Stage 3 (P) Checklist: Pre-Handover (The Soft LandingsFramework Australia and New Zealand, CIBSE ANZ 1/2014) 
In order to carry out this proposed research successfully, a new item named Building Defects Management Program will be introduced as Checklist P13 of SL Framework Level 3because of the following reasons:

\section{Environmental and energy logging review}

Item P1 is referring to responsibilities on co-ordination of data recording. This is more on efficient data recording routine due to be carried out by respective technical personnel. This is purely a routine data-based exercise and is not related to physical building defects.

\section{Building readiness programme}

Item P2 is referring to completed site with regards to mechanized metering system which requires co-ordinated testing and commissioning (T\&C) activities, trainings on installed system at the newly completed building including setting up, checking the functionality of energy meter, fiscal meter and energy monitoring software (if any). This is under electrical mechanized system and does not have any direct impact on structural building defects.

\section{Commissioning records check}

Item P3 is referring to commissioning records on true power consumed by fan motors, post-completion commissioning and fine-tuning. This is a mechanical based requirement and is not related to any form of physical building defects.

\section{Review Performance Metrics}

Item $\mathrm{P} 4$ is to review and revise performance metrics and design targets. Performance metrics is a practical product or tool that can track safety and health performance using leading, lagging and financial metrics in the construction industry, and can also be scaled to an organization's size for its own use. Measuring safety and health performance in the workplace has been a challenge, particularly in the construction industry which consists of large numbers of mostly small employers where numerous parties are responsible for managing health and safety risks. This is a tracking exercise on safety and health performance as well as design review. These are social and process-based requirements and do not contribute to physical nor structural building defects

\section{Maintenance contract}

Item P5 is referring to maintenance services made available immediately after handover bound by the contract. Focus of the proposed research is to determine the impact or influence (if any) by this selected Level 3 Checklist on number of defects at handover. Thus, this particular checklist item is considered redundant. (It is like purposely preparing extra work for the undesired building defects)

\section{Compile a guide for occupants}

Item P6 is generally on the O\&M manuals and logbook which is parallel to our practice in Malaysia. However, these O\&M manuals are basically for the Mechanical and Electrical Engineering personnel to adapt to on scheduled basis after handover. This is not meant for random building defects that occur as and when, and thus not related to physical defects at handover.

\section{Compile a technical guide}

Item P7 is similar to Item P6 where manuals are prepared for clear usage or handling of systems installed in the building. This is clearly a routine or knowledge on how to handle / operate equipment or systems in the respective building. This item is a mechanical, electrical and systembased requirement ready to be used at any point of time and thus not related to building defects at handover.

\section{Training}

Item P8 is more on preparing trained and skilled personnel to deliver the requirements as stipulated in Items P6 and P7. In other words, this item is a complementary item to P6 and P7 which service is required for both scheduled and on-call basis. Similarly, this is apparently not related to physical building defects at handover.

\section{Building management system interface completion and demonstration}

Item P9 is similar to Item P8 which is to prepare trained personnel or operators to run and operate the building management system (BMS) installed and any allied controls in the building. This is a system-based requirement ready to be used at any point of time and thus not related to building defects at handover.

\section{Migration planning}

Item P10 is not a current practice in Malaysia whereby migration planning clashes with site activities. No such migration or move-in programme is not allowed until Certificate of Completion (CPC) and Certificate of Completion and Compliance (CCC) are fully complied and issued to both awarded Contractor and Client respectively. In addition to this requirement, the building to be occupied needs to get Building Inspection Approval by 'Bomba' before any migration planning can be made. Apparently, some of the policy and requirements practised in United Kingdom, Australia and New Zealand differ from our JKR 203A Contracts practised in Malaysia. As such, this item is not relevant and cannot be implemented in our local construction industry.

\section{Aftercare team home}

Item P11 is a preparation for any event as per required or needed after handover. To provide a visible and accessible workplace in the new building for aftercare team from day 1 is a norm practice in Malaysia. However, the research is to focus on number of building defects at handover, and to prepare such requirement for events after building has been handed-over or occupied is kind of like ignoring or not bothered much by the building quality at handover. Thus, this particular checklist item is considered redundant.

\section{O\&M manual review}

Item P12 is referring to Items P6 and P7 in the context of getting the O\&M manual reviewed with facilities manager and signed off when it is complete and acceptable. As explained earlier, this O\&M manual is basically meant for the Mechanical and Electrical Engineering personnel to 
Adapt to on scheduled basis and on-call basis after handover, and thus not related to building defects at handover.

The new checklist item that is about to be introduced in this study is Building Defects Management Program:

\section{Building Defects Management Program (BDMP)}

The team should review JKR 203A Form of Contracts with PWD personnel, who has the authority as policy maker to revise the existing Form of Contracts to help reduce the number of building defects at handover should it be viable to do so.

\section{Case Study Sampling}

The intended samples will be taken from completed buildings at 3 selected public universities within Klang Valley area. Universities to be approached are those receiving the top three highest $10^{\text {th }}$ Malaysia Plan (10MP) funding from Ministry of Higher Education Malaysia or currently known as Ministry of Education of Malaysia. This 10MP funding is not only for projects filtered and approved by Ministry for its 5-year period a head but also for pending $9^{\text {th }}$ Malaysia Plan (9MP) projects that have yet to be completed within these 2011-2015 allocation years. The yearly distribution of 10MP funding by Ministry on all public universities is illustrated in the following Figure 5.

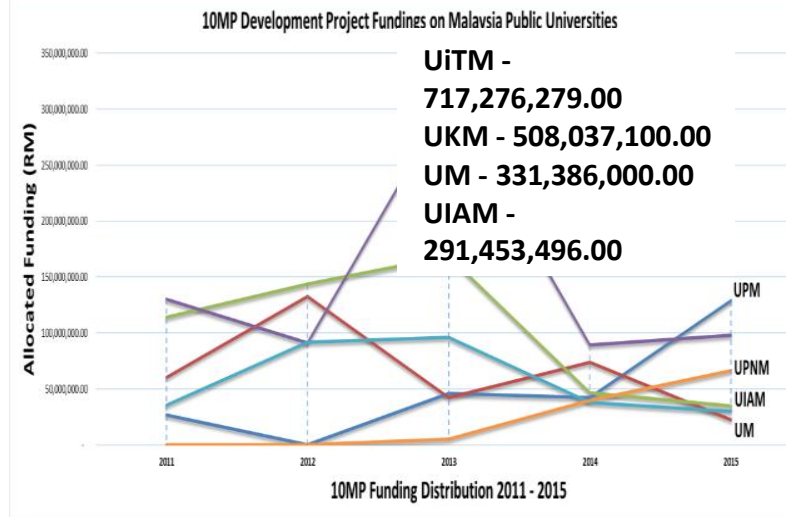

Fig. 5 10MP Funding Distribution on Public Universities in Malaysia (2011-2015)

(Source: Development Division, Ministry of Higher Education, Malaysia, 2015)

There are 6 public universities within Klang Valley area. Based on the chart shown in Figure 5, the top 3 universities receiving the highest 10MP funding in descending order are Universiti Teknologi Mara (UiTM), Universiti Kebangsaan Malaysia (UKM) and Universiti Malaya (UM). However, selection of UM as a sample has to be disqualified to avoid bias because student is UM staff directly involved in development projects funded by the Ministry. As such, Universiti Islam Antarabangsa Malaysia (UIAM) being the fourth highest 10MP funded university has been selected to replace UM as the third case study sample.Sub-sampling from these 3 universities will be selected based on the following criteria among which are: projects under 10MP funding, specifically funded under Direct Expenditure (DE), being managed by respective university themselves (not by JKR), categorized under G7 (Building Works) i.e.
RM10Millions worth of project and above, and is/are completed buildings with up to 3 years of occupancy.

As mentioned earlier, this newly introduced item P13 Building Defects Management Program (BDMP) will very much relate to some contractual items in JKR 203A Form of Contracts observed to be among the most potential contributing factors to defected buildings at handover. In this proposed research, besides recording the number of building defects at handover, data collection will also look into the history of vital processes such as Pre-Handover Inspection (Pre-CPC), Testing \& Commissioning (T\&C), submission of Building User Manual or widely known as O\&M (Operation \& Maintenance) Manual during handover as well as choice of Performance Bond for project favoured by awarded contractor. Result analyses will be used to identify the relationship between defects during building handover and BDMP, if any.

From here, SL Framework Level 3 will be set up where views and feedback on contractual items from stakeholders will be used for further discussion with PWD personnel as authorised policy maker. The outcome of the discussion is expected to verify on the need to possibly improvise some of the items in JKR 203A Forms of Contracts observed by stakeholders to be contributing to current defect issues at handover. Further effort is expected for implementation should consensus acceptance by stakeholders on SL Framework Level 3 is verified.

\section{CONCLUSIONS}

The outcome of the study is expected to affirm the relationship between defects during building handover and Soft Landings approach at public universities within Klang Valley area. It is also aimed to set up Soft Landings Framework Level 3 Model (Pre-Handover)and to fully develop Building Defects Management Program (BDMP)in this framework as a platform to help reduce the number of defects at handover, provide clients and end-users the buildings that comply to their expectation in long term run. Conclusive and overall remarks from stakeholders obtained from this research will substantiate the need to improvise the existing JKR 203A Forms of Contracts items among which are the positioning of As-built Drawings as a Preliminary item, the option of using "WJP" (Wang Jaminan Pelaksanaan) as retentions rather than Performance Bond, release of $50 \%$ of Performance Bond after CPC is issued and also O\&M manuals being part of the Contracts instead of being part of CCC mandatory submissions. Following this research, it is hoped that further effort can be taken to get this Building Defects Management Program be officially implemented. New buildings shall be delivered with smooth transition and handed over with minimal possible defects as well as improved building quality standard should this development be tabled and approved by the Cabinet of Malaysia one day. 


\section{REFERENCES}

1. Abdul Lateef Ol anrewaju, A. (2012). Quantitative Analysis of Defects in University Buildings: User Perspective. Built Environment Project and Asset Management, Vol. 2, No.2, 2012, pp 167-181.

2. Burati, J.L., Farrington, J.J. and Letbetter, W.B. (1992). Causes of Quality Deviations in Design and Construction. Journal of Construction Engineering and Management, Vol. 118, Issue 1, 1992.

3. Designing Buildings Wiki "Soft Landings", BSRIA, 2015.

4. Eizzatul Ain, S., Hishamuddin, M.A. and Suwaibatul Islamiah, A.S. (2012). A Review of the Effect of Building Design on Maintenance Management. $3^{\text {rd }}$ International Conference on Business and Economic Research ( $3^{\text {rd }}$ ICBER 2012) Proceeding.

5. Josephson, P.-E. and Hammarlund, Y. (1999). The Causes and Costs of Defects in Construction: A Study of Seven Building Projects. Journal of Automation in Construction, Vol. 8, Issue 6, pp 681-687, 1999.

6. Love, P.E.D. and Josephson, P.E. (2004). Role of Error-Recovery Process in Projects. Journal of Management in Engineering, Vol. 20, Issue 2, 2004

7. Love, P.E.D., Lopez, R. and Edwards, D.J. (2013). Reviewing the Past to Learn in the Future: Making Sense of Design Errors and Failures in Construction. Journal of Structure and Infrastructure Engineering: Maintenance, Management, Life Cycle Design and Performance, Vol. 9, Issue 7, 2013.

8. Mark Way (2005). Soft Landings: A Fresh Scope of Service that Ensures Users and Clients Get the Best Out of a New Building. Journal of Facilities Management, Vol. 4, No. 1, 2005, pp 23-39.

9. Schultz, C.S., Jorgensen, K., Bonke, S., Mikael, G. and Rasmussen, G. (2015). Building Defects in Danish Construction: Project Characteristics Influencing the Occurrence of Defects at Handover. Architectural Engineering and Design Management, Vol. 11, No. 6, 2015, pp 423-439.

10. Soft Landings: Cloosing the Loop, BSRIA 2/2012.

11. The Soft Landings Framework Australia and New Zealand: For Better Briefing, Handover and Building Performance in Use. CIBSE ANZ $1 / 2014$.

12. The Soft Landings Framework UBT BSRIA - For Better Briefing, Handover and Building Performance in Use. BSRIA BG 4/2009.

13. The Sun (25 May 2007), The Star (25 April 2007, 3 June 2009, 20 February 2013), Utusan (3 June 2009) and Bernama (21 February 2013).

14. Zawawi, E.M.A. and Kamaruzzaman, S.N. (2010). Assessment of Building Maintenance Management in Malaysia: Resolving Using a Solution Diagram. Journal of Retail \& Leisure Property, Vol. 9, Issue 4, 2010, pp 349-356. 